\title{
The relationship between fitness levels and metabolomic profiles in healthy adults
}

\author{
C. Morris, C. O. Grada, M. Ryan, M. Walsh, M. J. Gibney, H. M. Roche, G. De Vito, M. J. Gibney, \\ E. Gibney and L. Brennan \\ UCD Institute of Food and Health, University College Dublin, Belfield, Dublin 4, Republic of Ireland and UCD Institute for \\ Sport and Health, University College Dublin, Belfield, Dublin 4, Republic of Ireland
}

\begin{abstract}
Metabolomics is the study of metabolites in biological samples and its application in the field of nutrition and health is increasing exponentially. While much effort has been invested in understanding factors that influence the metabolomic profile there is relatively little known about the effect, fitness level has on the metabolite composition of biofluids. This study aimed to establish the relationship between fitness level, substrate oxidation rates and the metabolomic profile.

Two hundred and fourteen healthy adults aged 18-60 years were recruited as part of a metabolic challenge study. The volunteers underwent a sub maximal four stages $\mathrm{VO}_{2}$ test and had detailed body composition analysis performed. Fasting urine and blood samples were collected. A cohort of sixty-seven subjects (thirty-five male, thirty-two female) were selected based on their estimated $\mathrm{VO}_{2 \text { max }}$ levels and their biofluid samples were analysed using NMR- and GC-MS-based metabolomics. The subjects were split into fitness groups according to their $\mathrm{VO}_{2 \max }$ levels $(\mathrm{ml} / \mathrm{kg} / \mathrm{min})$ : females $\mathrm{VO}_{2 \max }<32$; females $\mathrm{VO}_{2 \max }>43$; males $\mathrm{VO}_{2 \max }<44 ;$ males $\mathrm{VO}_{2 \max }>57$.

Statistical analysis of the data revealed significant differences in normalised fat and carbohydrate oxidation levels between the fitness groups for females at $15 \%$ and $35 \%$ and males at $35 \%$ of their maximum power output. Females in the high fitness group had significantly higher fat oxidation levels compared to the low fitness group (at $35 \%, 0.55 \pm 0.20 \mathrm{mg} / \mathrm{min} / \mathrm{ffm}$ compared to $0.33 \pm 0.28 \mathrm{mg}$ / $\mathrm{min} / \mathrm{ffm}, P=0.024)$. Males at $35 \%$ of their power output also had significantly higher fat oxidation levels $(0.48 \pm 0.23 \mathrm{mg} / \mathrm{min} / \mathrm{ffm} v$. $0.31 \pm 0.22 \mathrm{mg} / \mathrm{min} / \mathrm{ffm}, P=0.036$ ). Analysis of the oxygen kinetic data also revealed significant differences between the groups. Both males and females in the high fitness group had significantly decreased recovery time at $55 \%$ and $75 \%$ of their maximum power output (for females: $69.0 \pm 15.0 \mathrm{~s} v .81 .5 \pm 17.1 \mathrm{~s}$ at $55 \%$ maximum power output and $81.0 \pm 22.0 \mathrm{~s} v .120 .5 \pm 44.0$ at $75 \%$ maximum power output, $P=0.026$ and $P<0.001)$.

Metabolomic analysis of the urine samples revealed significantly different profiles in the fitness groups with the differences being more pronounced in the females. A total of twenty amino acids and derivatives were significantly lower in females in the high fitness group. For males, only four amino acids were significantly different. Statistical analysis of the data also revealed correlations in females between 13 amino acid levels in the urine and normalised fat oxidation at $15 \%$ of the maximum power output. In conclusion, this study demonstrates a relationship between fitness level and the metabolomic profile. Moreover, the metabolite changes show that a reduced excretion of amino acids in adults is associated with increased fitness levels and an increased fat oxidation rate during exercise.
\end{abstract}

This work was conducted as part of a clinical trial (NCT01172951), funded under the Food for Health Research Initiative (NDP 2007-2013; 07FHRIUCD1) by the Department of Agriculture, Fisheries and Food, the Health Research Board and the Department of Health and Children. 